\title{
Estação sensorial temática: recurso pedagógico para formação do cirurgião-dentista na produção do cuidado em saúde
}

\author{
Lila Louise Moreira Martins Franco*; Leandro Brambilla Martorell**; Liliane Braga Monteiro dos \\ Reis***; Giovana Galvão Tavares**** \\ * Doutoranda em Educação, Universidade de Brasília (UnB), \\ Professora Adjunta, Centro Universitário de Anápolis, \\ UniEVANGÉLICA \\ ** Professor Doutor, Universidade Federal de Goiás (UFG) e \\ Centro Universitário de Anápolis, UniEVANGÉLICA \\ *** Professora Doutora, Centro Universitário de Anápolis, \\ UniEVANGÉLICA \\ **** Coordenadora do Programa de Pós-Graduação em Sociedade, \\ Tecnologia e Meio Ambiente, Centro Universitário de \\ Anápolis. UniEVANGÉLICA
}

Recebido em 31/08/2017. Aprovado em 08/11/2017.

\begin{abstract}
RESUMO
A estação sensorial temática é um recurso pedagógico que utiliza imagens fotográficas e/ou objetos em determinado espaço da sala de aula ("estação"), para que os estudantes percebam os materiais utilizando seus cinco sentidos e com o objetivo de conduzi-los a reflexões. O mencionado recurso foi proposto na formação de cirurgiões-dentistas, para sensibilizar os participantes na produção do cuidado em saúde com foco na conduta profissional a ser tomada em diferentes contextos. Este artigo busca apresentar os resultados da aplicação da estação sensorial temática como prática pedagógica, tendo como base a experiência desenvolvida nas disciplinas da área de Saúde Coletiva, no curso de Odontologia. Trata-se de relato de experiência e tem abordagem descritiva e reflexiva. Considera-se que a aplicação de um recurso pedagógico voltado para os cinco sentidos inova o processo ensinoaprendizagem, além de sensibilizar quanto a uma prática profissional a ser sentida e desenvolvida de forma humanizada, tanto no âmbito individual quanto coletivo.

Descritores: Formação de Conceito. Educação em Saúde. Odontologia. Educação em Odontologia.
\end{abstract}

\section{INTRODUÇÃO}

Os cinco sentidos, ou seja, tato, visão, paladar, olfato e audição são utilizados de diversas maneiras e em diversos contextos das relações sociais humanas. Na área da saúde, tradicionalmente, alguns desses sentidos são explorados, por exemplo, para auscultar o coração e pulmões (audição), identificar a topografia de lesões e dores (tato) e identificar odores característicos de determinadas infecções 
(olfato). Assim, durante o processo de ensinoaprendizagem é importante que os docentes conduzam atividades que permitam o desenvolvimento dessas habilidades sensoriais.

Entretanto, a exploração dos sentidos em atividade pedagógica também pode almejar objetivos para além de uma clínica que busca identificar sinais e sintomas biológicos do corpo humano, no intuito de se realizar um diagnóstico específico $^{1}$. O uso dos sentidos também pode servir no desenvolvimento de habilidades relacionais conectadas com a percepção do outro, humanização das relações e com a produção do cuidado.

Desse modo, os órgãos do sentido servem tanto para o reconhecimento das funções triviais como visão, olfato, paladar, audição e tato, quanto para a complexa associação destas funções com as manifestações comportamentais diante das fontes destes estímulos ${ }^{2}$. O uso dos sentidos parte do biológico, entretanto, as experiências pedagógicas a partir do uso dos sentidos não estão limitadas exclusivamente e nem mesmo principalmente a este componente. Para a formação direcionada para a produção do cuidado destacam-se as interfaces entre a percepção sensorial (biológica) e o que ela permite reconhecer em relação à expressão comportamental, por exemplo.

A utilização dos cinco sentidos nas práticas pedagógicas, ao contribuir para a formação voltada para o cuidado, dialoga com os preceitos da Clínica Ampliada. A formação generalista do cirurgião-dentista também deve estar em consonância com a humanização das relações que, segundo a Política Nacional de Humanização ${ }^{3}$ deve acontecer nos diferentes níveis de atenção do sistema de saúde. Assim, é essencial que estas práticas se fundamentem por meio do compromisso do sujeito e seu coletivo, na busca da produção de saúde, partindo de diferentes práticas terapêuticas.
Além disso, a experiência pedagógica que aborda os cinco sentidos pode favorecer a aprendizagem significativa, uma vez que o estudante vivencia de modo mais integral a proposta em sala de aula. Para Moreira, Caballero e Rodríguez ${ }^{4}$, a aprendizagem significativa é o processo pelo qual se articula um conhecimento ainda não visto com o que o aprendiz possui de estrutura cognitiva e a partir desta articulação o material de aprendizagem passa a ser introjeção para o sujeito.

Pensando na necessidade de formação de sujeitos implicados com a produção do cuidado na formação em Odontologia, um grupo de docentes do curso de Odontologia do Centro Universitário de Anápolis/UniEVANGÉLICA, buscou colocar em prática um recurso pedagógico que fosse capaz de ao mesmo tempo possibilitar essa formação de modo significativo e lançando mão do uso dos sentidos. Assim, propuseram uma estratégia batizada de "estação sensorial temática".

A utilização deste recurso pedagógico se dá por meio da alocação de imagens fotográficas e/ou objetos em determinado espaço da sala de aula ("estação"), para que os acadêmicos vivenciem este material e sejam sensibilizados a refletir sobre a conduta profissional a ser tomada em diferentes contextos. Após o momento de experimento e sensibilização, o professor coordena a discussão sobre os significados da experiência para os estudantes.

O objetivo deste estudo é apresentar a estação sensorial temática como uma prática pedagógica com potencial de redirecionar a produção de sujeitos implicados com a produção do cuidado na formação em Odontologia, tendo como base a experiência desenvolvida no curso de Odontologia do Centro Universitário de Anápolis/ UniEVANGÉLICA em disciplinas da área de Saúde Coletiva. 


\section{METODOLOGIA}

O presente trabalho se refere a um relato de experiência do tipo descritivo e reflexivo. Como apoio foram analisados os planos de aula de cada conteúdo programático em que se propôs o uso da "estação sensorial temática" relacionada a três conteúdos referentes à saúde coletiva: promoção e educação em saúde (conteúdo 1), Política Nacional de Atenção Básica (conteúdo 2) e Sistema Único de Saúde: direito à saúde (conteúdo 3).

Um diário de campo construído pela docente responsável pelas atividades foi instrumento auxiliar para a análise dos resultados da metodologia utilizada em aula. O uso de diário de campo permite o aprofundamento do conhecimento da realidade a partir do registro das impressões do pesquisador ${ }^{5}$. Sendo os pesquisadores deste relato a professora que desenvolveu a metodologia junto a seus pares.

A atividade proposta aconteceu em uma aula com duração de duas horas e 30 minutos, dividida em duas partes com um intervalo de 20 minutos. O número de acadêmicos presentes em cada atividade foi em torno de 14 pessoas.

Cada conteúdo proposto possui um número específico de estações que foram organizadas de forma a trazerem ideias-chave sobre os diferentes temas.

A observação dos estudantes foi feita a partir da dinâmica de uso do recurso pedagógico, mediante a vivência com este material. Para cada conteúdo foram identificados temas, por isso "estações sensoriais temáticas" que foram representadas com o material mais pertinente, imagens fotográficas, ou objetos, para sensibilizar o estudante em formação. Os estudantes tinham de 2 a 5 minutos para esta observação conforme fosse necessário em cada estação, passando assim, por todas as estações relacionadas ao conteúdo da aula. Num segundo momento, após experimentação e sensibilização, o professor fez a mediação entre a teoria e os significados da experiência para os estudantes.

Este relato de experiência se dá frente a temáticas específicas expostas dentro de cada conteúdo, isto é, os pesquisadores buscaram dentro do plano de aula características específicas das estações. Assim, puderam identificar quais os sentidos eram explorados em cada uma das estações e, sequencialmente, como que a experiência pela estação poderia potencialmente redirecionar a formação dos estudantes para o cuidado, conectada com os preceitos da clínica ampliada ${ }^{9}$. Por fim, avaliaram o diário de campo construído pela professora responsável pelas atividades e, assim, puderam identificar elementos que sinalizasse uma formação mais sensível ao cuidado e conectada com as propostas da clínica ampliada, conforme previsto na Política Nacional de Humanização ${ }^{8}$.

A estação sensorial temática foi desenvolvida em disciplinas da área saúde coletiva, em um curso de graduação em Odontologia, de um município de médio porte do Brasil durante o primeiro semestre de 2017.

\section{RESULTADOS}

Para a apresentação dos resultados sobre a análise dos planos de aula, optou-se pela construção de quadros-sínteses com as ideiaschave categorizadas assim: temas; estações; sentidos; interface, cuidado e clínica ampliada. O conteúdo Promoção e educação em saúde trabalhado no $2^{\circ}$ período do curso (quadro 1 ); Política Nacional de Atenção Básica trabalhada no $3^{\circ}$ período (quadro 2), Sistema Único de Saúde (SUS) e o direito à saúde trabalhada no $7^{\circ}$ período (quadro 3).

Em relação à análise do diário de campo, notou-se que os acadêmicos apresentaram diferentes reações frente a esta proposta, tais como: curiosidade pelo que estava sendo 
exposto; estranhamento ao não vislumbrarem relação com o conteúdo proposto; e, por fim, a relação da teoria-prática, após discussão com a docente da disciplina, quanto a cada uma das estações. A curiosidade foi notada por meio de comentários realizados entre eles sobre o que estavam manuseando, expressando desejo de entender o que visualizavam, em algumas das estações ouvindo, em outras provando o sabor, na busca da conexão entre os sentidos.

Quadro 1. Área temática: Promoção e educação em saúde

\begin{tabular}{|c|c|c|}
\hline Descrição das estações & $\begin{array}{c}\text { Desenvolvimento } \\
\text { dos sentidos }\end{array}$ & $\begin{array}{c}\text { Implicações para o cuidado e } \\
\text { clínica ampliada }\end{array}$ \\
\hline $\begin{array}{l}\text { 1. Mesa com biscoito de polvilho e } \\
\text { café expostos com um forro de mesa } \\
\text { (chita). }\end{array}$ & $\begin{array}{l}\text { Paladar } \\
\text { Visão } \\
\text { Tato }\end{array}$ & $\begin{array}{l}\text { Empatia necessária na relação } \\
\text { profissional-paciente }\end{array}$ \\
\hline $\begin{array}{l}\text { 2. Livro sobre direito à saúde, } \\
\text { folheto sobre informações de cida- } \\
\text { dania como registro geral e cadastro } \\
\text { de pessoa física, e dinheiro de } \\
\text { brinquedo. }\end{array}$ & $\begin{array}{l}\text { Tato } \\
\text { Visão }\end{array}$ & $\begin{array}{l}\text { Organização política no exercício } \\
\text { profissional enquanto compromisso } \\
\text { ético para sua atuação }\end{array}$ \\
\hline $\begin{array}{l}\text { 3. Livros formativos referentes a } \\
\text { literatura brasileira e informativos } \\
\text { quanto à localidade regional e } \\
\text { internacional. }\end{array}$ & $\begin{array}{l}\text { Tato } \\
\text { Visão }\end{array}$ & $\begin{array}{l}\text { Sensibilização para os conceitos de } \\
\text { educação formal, não-formal, e } \\
\text { informal importantes como base } \\
\text { epistemológica para o exercício } \\
\text { profissional na educação em saúde }\end{array}$ \\
\hline $\begin{array}{l}\text { 4. Material impresso referente à } \\
\text { educação popular e recursos } \\
\text { educativos (panfleto e folder) com } \\
\text { caráter problematizador. }\end{array}$ & $\begin{array}{l}\text { Tato } \\
\text { Visão }\end{array}$ & $\begin{array}{l}\text { Definição quanto ao saber popular e a } \\
\text { representação da educação problema- } \\
\text { tizadora }\end{array}$ \\
\hline $\begin{array}{l}\text { 5. Livros com o saber científico } \\
\text { (conhecimento sistematizado). }\end{array}$ & $\begin{array}{l}\text { Tato } \\
\text { Visão }\end{array}$ & $\begin{array}{l}\text { Definição quanto ao saber científico e } \\
\text { a representação da educação bancária }\end{array}$ \\
\hline $\begin{array}{l}\text { 6. Objetos como carro de boi e } \\
\text { trouxas de pano em miniatura, livro } \\
\text { "O que é Cultura" e literatura de } \\
\text { cordel. Áudio contextualizado com } \\
\text { a formação cultural de cada } \\
\text { acadêmico(a), mediante ambienta- } \\
\text { ção do espaço educativo da sala de } \\
\text { aula com seleção de músicas pelos } \\
\text { próprios acadêmicos. }\end{array}$ & $\begin{array}{c}\text { Tato } \\
\text { Visão } \\
\text { Audição }\end{array}$ & $\begin{array}{l}\text { Sensibilização quanto à cultura } \\
\text { regional e suas possíveis interfe- } \\
\text { rências na relação profissional- } \\
\text { paciente e na determinação social do } \\
\text { processo saúde-doença }\end{array}$ \\
\hline $\begin{array}{l}\text { 7. Homens de brinquedo em } \\
\text { miniatura dispostos em círculo } \\
\text { juntamente com a literatura de } \\
\text { cordel sobre "Zumbi e os palmares" }\end{array}$ & $\begin{array}{l}\text { Tato } \\
\text { Visão }\end{array}$ & $\begin{array}{l}\text { Representação dos movimentos } \\
\text { sociais e suas repercussões na saúde } \\
\text { durante o exercício profissional }\end{array}$ \\
\hline
\end{tabular}


Quadro 2. Área temática: Política Nacional de Atenção Básica

\begin{tabular}{|c|c|c|}
\hline Descrição das estações & $\begin{array}{l}\text { Desenvolvimento } \\
\text { dos sentidos }\end{array}$ & $\begin{array}{c}\text { Implicações para o cuidado e } \\
\text { clínica ampliada }\end{array}$ \\
\hline $\begin{array}{l}\text { 1. Diário de campo com mapa do } \\
\text { território adstrito de uma unidade de } \\
\text { saúde da família com duas equipes. }\end{array}$ & $\begin{array}{l}\text { Visão } \\
\text { Tato }\end{array}$ & $\begin{array}{l}\text { Responsabilidade sanitária sobre o } \\
\text { território e influência do território } \\
\text { na determinação social da saúde }\end{array}$ \\
\hline $\begin{array}{l}\text { 2. Imagem demonstrando a realização } \\
\text { do teste do pezinho. }\end{array}$ & Visão & $\begin{array}{l}\text { Sensibilização para o acesso } \\
\text { universal e contínuo a serviços de } \\
\text { saúde com qualidade e resolutivos }\end{array}$ \\
\hline $\begin{array}{l}\text { 3. Imagem demonstrando a } \\
\text { comemoração festiva de } 79 \text { anos de } \\
\text { um homem. }\end{array}$ & Visão & $\begin{array}{l}\text { Percepção sobre a história e rotina } \\
\text { dos pacientes e exercício de } \\
\text { empatia }\end{array}$ \\
\hline $\begin{array}{l}\text { 4. Áudio da música "Roda Viva" } \\
\text { Chico Buarque. }\end{array}$ & $\begin{array}{l}\text { Audição } \\
\text { Visão }\end{array}$ & $\begin{array}{l}\text { Influência dos determinantes } \\
\text { sociais e políticos na vida das } \\
\text { pessoas }\end{array}$ \\
\hline 5. Casa de madeira em miniatura. & Tato & $\begin{array}{l}\text { Percepção sobre as especificidades } \\
\text { locoregionais e condições de } \\
\text { moradia }\end{array}$ \\
\hline $\begin{array}{l}\text { 6. Imagens que demonstram desde a } \\
\text { gestante no pré-natal até o } \\
\text { acompanhamento do bebê, mais } \\
\text { imagem sobre rede de atenção. }\end{array}$ & Visão & $\begin{array}{l}\text { Atenção holística e multipro- } \\
\text { fissional aos pacientes }\end{array}$ \\
\hline $\begin{array}{l}\text { 7. Diário de campo demonstrando a } \\
\text { imagem desenhada da infraestrutura } \\
\text { da Unidade Básica de Saúde da } \\
\text { Família, seus instrumentais e insumos } \\
\text { (miniaturas) }\end{array}$ & $\begin{array}{l}\text { Visão } \\
\text { Tato }\end{array}$ & $\begin{array}{l}\text { Condições materiais para o } \\
\text { exercício da clínica odontológica }\end{array}$ \\
\hline $\begin{array}{l}\text { 8. Esquema com bonecos em } \\
\text { miniatura } \\
\text { composição da equipe multipro- } \\
\text { fissional. }\end{array}$ & $\begin{array}{l}\text { Visão } \\
\text { Tato }\end{array}$ & $\begin{array}{l}\text { Atenção holística e multipro- } \\
\text { fissional aos pacientes }\end{array}$ \\
\hline $\begin{array}{l}\text { 9. Notícia veiculada na internet sobre } \\
\text { "Risco de febre amarela em Minas } \\
\text { Gerais". }\end{array}$ & Visão & $\begin{array}{l}\text { Influência da determinação social } \\
\text { da saúde, em especial, dos } \\
\text { componentes ambientais e } \\
\text { políticos }\end{array}$ \\
\hline $\begin{array}{l}\text { 10. Comida no palito que poderia ser } \\
\text { degustada, mas, com a regra de } \\
\text { sempre manterem o braço estendido, } \\
\text { sem flexionar em momento algum. }\end{array}$ & Paladar & $\begin{array}{l}\text { Importância do trabalho multipro- } \\
\text { fissional ser realizado em equipe }\end{array}$ \\
\hline
\end{tabular}


Quadro 3. Área temática: Sistema Único de Saúde (SUS) e o direito à saúde

\begin{tabular}{|c|c|c|}
\hline Descrição das estações & $\begin{array}{l}\text { Desenvolvimento } \\
\text { dos sentidos }\end{array}$ & $\begin{array}{l}\text { Implicações para o cuidado e } \\
\text { clínica ampliada }\end{array}$ \\
\hline $\begin{array}{l}\text { 1. Mesa com café, castanhas, bolos e } \\
\text { artesanatos característicos de deter- } \\
\text { minada região do estado de Goiás; carros } \\
\text { e dinheiro de brinquedo; objetos alusivos } \\
\text { à complexidade da realidade locore- } \\
\text { gional do território dos municípios } \\
\text { vinculados à Regional Pirineus } \\
\text { orientações escritas aos acadêmicos. } \\
\text { Região de Saúde/Organização do SUS. }\end{array}$ & $\begin{array}{l}\text { Paladar } \\
\text { Visão } \\
\text { Tato } \\
\text { Olfato }\end{array}$ & $\begin{array}{l}\text { Empatia necessária na relação } \\
\text { profissional-paciente }\end{array}$ \\
\hline $\begin{array}{l}\text { 2. Casa de maquete com informações } \\
\text { impressas sobre a realidade do SUS } \\
\text { representando as portas de } \\
\text { entrada/organização do SUS. }\end{array}$ & $\begin{array}{c}\text { Tato } \\
\text { Visão }\end{array}$ & $\begin{array}{l}\text { Sensibilização quanto ao acesso } \\
\text { universal à saúde por meio das } \\
\text { portas de entrada no SUS. }\end{array}$ \\
\hline $\begin{array}{l}\text { 3. Bonecos representando recursos } \\
\text { humanos; cédulas de dinheiro de cunho } \\
\text { lúdico e mapa da regional pireneus e } \\
\text { mapa do Brasil representando o mapa da } \\
\text { Saúde/ Planejamento da Saúde }\end{array}$ & $\begin{array}{c}\text { Tato } \\
\text { Visão }\end{array}$ & $\begin{array}{l}\text { Formação para a prática do } \\
\text { planejamento em saúde coletiva } \\
\text { implicando na lógica da prática do } \\
\text { planejamento em saúde em âmbito } \\
\text { individual. }\end{array}$ \\
\hline $\begin{array}{l}\text { 4. Objetos lúdicos representando as } \\
\text { ações e serviços de saúde e } \\
\text { medicamentos essenciais Protocolo } \\
\text { Clínico e Diretriz Terapêutica/ Assis- } \\
\text { tência à Saúde }\end{array}$ & $\begin{array}{l}\text { Tato } \\
\text { Visão }\end{array}$ & $\begin{array}{l}\text { Sensibilização para os protocolos } \\
\text { clínicos e diretriz terapêutica/ } \\
\text { assistência à saúde que implica em } \\
\text { postura reflexiva quanto ao que } \\
\text { está posto e a necessidade de } \\
\text { pensar a realidade de cada um dos } \\
\text { pacientes. }\end{array}$ \\
\hline \begin{tabular}{lll} 
5. Bonecos & \multicolumn{2}{c}{ representando entes } \\
federativos & enquanto & Comissões \\
Intergestores/ & Articulação & Interfedera- \\
tiva & &
\end{tabular} & $\begin{array}{c}\text { Tato } \\
\text { Visão }\end{array}$ & $\begin{array}{l}\text { Formação política quanto a } \\
\text { instâncias de participação social } \\
\text { para enfrentamento dos determi- } \\
\text { nantes da saúde. }\end{array}$ \\
\hline $\begin{array}{l}\text { 6. Material impresso representando um } \\
\text { exemplo de Contrato Organizativo da } \\
\text { Ação Pública em Saúde (COAPS). }\end{array}$ & Visão & $\begin{array}{l}\text { Formação para o planejamento em } \\
\text { saúde com proposição de ações } \\
\text { para atendimento individual e } \\
\text { coletivo. }\end{array}$ \\
\hline $\begin{array}{l}\text { 7. Negatoscópio com exame radio- } \\
\text { gráfico representando as Redes de } \\
\text { Atenção em Saúde }\end{array}$ & $\begin{array}{c}\text { Tato } \\
\text { Visão }\end{array}$ & $\begin{array}{l}\text { Sensibilização para o } \\
\text { encaminhamento dentro do SUS } \\
\text { para cumprimento da assistência } \\
\text { integral. }\end{array}$ \\
\hline $\begin{array}{l}\text { 8. Fone de ouvido extra auricular com } \\
\text { letras impressas de músicas (O pulso/ } \\
\text { Titãs; O trabalhador/Seu Jorge) } \\
\text { representando os Serviços Especiais de } \\
\text { Acesso Aberto }\end{array}$ & $\begin{array}{l}\text { Tato } \\
\text { Visão } \\
\text { Audição }\end{array}$ & $\begin{array}{l}\text { Sensibilização quanto aos serviços } \\
\text { de saúde para pessoa com agravo ou } \\
\text { em situação laboral que necessita de } \\
\text { atendimento especial. }\end{array}$ \\
\hline
\end{tabular}


Ao mesmo tempo, se notou um estranhamento por parte de alguns indivíduos ao vivenciarem imagens e/ou objetos que aparentemente não conseguiam, em um primeiro momento, relacionar com a proposta da temática da disciplina. Os estudantes foram estimulados a compreender a conexão entre a experiência e o conteúdo teórico, ao questionarem os sentidos, demonstrando um posicionamento ativo frente à busca de conhecimento.

Após a discussão com a docente, as conexões foram sendo construídas coletivamente e as diferentes possibilidades de relação da experiência com a teoria foram um fator de surpresa para o grupo de estudantes. Por exemplo, a conexão de livros literários com a educação informal, enquanto discussão inserida no conteúdo da educação popular e problematizadora em saúde. Ainda, ao ouvirem a música "Roda Viva", de Chico Buarque, puderam evidenciar a relação com a participação social, prevista na Política Nacional de Atenção Básica. Por fim, até mesmo a experiência de degustar a castanha de baru, servida na aula referente ao Decreto n. 7.508/2011, conectou sentidos e possibilitou que o grupo a relacionasse com a questão cultural local, sendo um dos objetos que caracterizava o conceito de região de saúde, dentro da organização do SUS.

\section{DISCUSSÃO}

As principais reflexões encontradas durante o uso deste recurso pedagógico foram: i) empatia na relação paciente-profissional, ii) sensibilização quanto à cultura regional; iii) interferência na prática de educação em saúde em diferentes concepções (bancária ou problematizadora); iv) organização política e os movimentos sociais com repercussões na saúde; v) assistência integral e de acesso universal observando os determinantes sociais em saúde; vi) história e rotina dos pacientes; vii) responsabilidade sanitária; viii) atenção holística e. ix) atendimento multiprofissional dos pacientes.

As reflexões frente à experiência vivenciada pelos acadêmicos vêm ao encontro da proposta de produção do cuidado em saúde, principalmente sobre a postura de um profissional de saúde a ser constituída. Pode-se dizer que está alinhada às Diretrizes Curriculares Nacionais do curso de Odontologia ${ }^{6}$, pois estimula uma formação voltada para atuação em equipe multiprofissional, em que se pauta o diagnóstico em uma visão integral do paciente. Para além desta atuação, ainda cabe extrapolar o olhar meramente biológico e articular os fatores determinantes e condicionantes da saúde ${ }^{7}$ diante do enfrentamento da condição atual de saúde do paciente.

A finalidade é sensibilizar para o momento do atendimento clínico na produção do cuidado da saúde dos pacientes, quando cabe retomar os pressupostos da clínica ampliada pautados em: processo saúde-doença de forma ampliada; diagnósticos e terapêuticas compartilhadas entre a equipe de saúde; a ampliação do "objeto" de trabalho se opondo a focar na doença e sim na pessoa ou grupo de pessoas; na mudança dos "meios" ou instrumentos de trabalho que partam da escuta do outro e de si mesmo; e apoio aos profissionais de saúde na ruptura quanto à "neutralidade" e à desconsideração da subjetivade $^{8}$; tendo o Projeto Terapêutico Singular (PTS) como ferramenta para o desenvolvimento destes pressupostos ${ }^{9}$.

Esta prática do PTS traduz e remete a um processo terapêutico, seja para indivíduos ou para coletividades quanto à produção do cuidado em saúde ${ }^{9}$. Desse modo, quando se propõe que sejam desenvolvidos os sentidos para oportunizar experiências atitudinais se propicia uma introjeção cultural voltada para o outro, 
para o contexto, para uma abordagem muito além da doença e voltada ao indivíduo ou coletividades, que seja de forma realmente "ampliada" na clínica.

A proposta feita em relação às estações sensoriais temáticas buscou a sensibilização dos acadêmicos para uma prática profissional diferenciada, em que se mobilizou vários contextos reais, por meio das imagens e/ou objetos, que sinalizam o desenvolvimento de uma experiência significativa e contundente não apenas para uma formação cognitiva, como também para a formação atitudinal ${ }^{10}$.

Portanto, destaca-se que na formação em Odontologia a utilização de novas práticas pedagógicas podem redirecionar a produção de sujeitos, no sentido da produção do cuidado, como essenciais para que se proponha uma mudança de paradigma na atuação e formação do cirurgião-dentista.

$\mathrm{O}$ paradigma anterior à clínica contemporânea pautava-se na ciência moderna com posicionamentos fundamentados em visões fragmentadas do indivíduo, portanto se apresenta impotente diante de sinais e sintomas que não pertencem a doença alguma ${ }^{11}$. A clínica ampliada e compartilhada opõe-se a este paradigma de fragmentação para favorecer a compreensão do todo $^{12}$.

Desse modo, a estação sensorial temática contribui no processo ensino-aprendizagem de forma significativa quanto a aspectos voltados para a humanização no atendimento. Assim, forma para uma prática profissional voltada para os diferentes níveis de atenção, tais como: promoção, prevenção, educação, reabilitação em saúde. Existem relatos sobre a clínica ser abordada de forma muito fragmentada, com a não vinculação ao histórico de saúde dos usuários $^{1,13}$. A vivência na estação sensibilizou os estudantes para outra prática a partir de uma realidade proposta. A Clínica Ampliada parte do que há de diferente em cada sujeito, ou seja, o que interfere para que seus sinais e sintomas sejam diferenciados entre cada $u^{8}{ }^{8}$.

O cirurgião-dentista em formação, frente a algumas situações experienciais pedagógicas mais ativas, sejam hipotéticas ou reais, tem o estimulo para olhar para futuras condutas profissionais. Destaca-se o fato de aprender a olhar para além do que se vê aparentemente e enxergar as adjacências e o que provavelmente interfere na saúde das pessoas, como os fatores biopsicossociais.

Pode-se apontar sobre as estações que estas mobilizaram a habilidade de problematizar a realidade apresentada, o que direciona a formação e capacitação para atuar futuramente nos atendimentos clínicos de forma ampliada, ao se perceber enquanto mediador pedagógico.

Esse futuro profissional do serviço com o papel de mediador pedagógico contribuirá para educação em saúde junto à comunidade, atribuição comum a todos os profissionais conforme a Política Nacional de Atenção Básica $^{15}$, assim como em seu exercício profissional em âmbito clínico, à medida que os estágios curriculares supervisionados podem possibilitar esta formação ${ }^{14}$, por levarem em conta os serviços de saúde como locus de prática da Clínica Ampliada.

Há que se considerar que muitos elementos são fundamentais para o exercício da Odontologia no campo biológico e social, levando em consideração os fatores determinantes e condicionantes da saúde e que circundam o processo saúde-doença.

\section{CONCLUSÕES}

Os apontamentos feitos quanto à estação sensorial temática enquanto recurso pedagógico para formação do cirurgião-dentista, na perspectiva da produção do cuidado em saúde trouxe a reflexão sobre a necessidade de se 
mobilizar conhecimentos, seja no campo cognitivo, procedimental, e/ou atitudinal.

A prática odontológica requer um profissional de saúde que realmente preze pela "saúde" do paciente, opondo-se à visão reducionista da doença enquanto centro, deslocando da compreensão de outros fatores determinantes e condicionantes da saúde.

Cabe pensar propostas que sejam inovadoras na prática pedagógica, que estimulem futuros cirurgiões-dentistas a exercerem a Clínica Ampliada e compartilhada de forma contundente e não tangencial se exerça a clínica ampliada e compartilhada, pautada na visão de uma equipe articulada por interesses humanos a serem vivenciados junto a seus pacientes.

Conclui-se que aplicar um recurso pedagógico em uma perspectiva voltada para os cinco sentidos e que aproxima o estudante do conteúdo a ser abordado, é uma inovação do processo ensino -aprendizagem. Inovação na direção de sensibilizá-lo para uma prática profissional a ser sentida e desenvolvida de forma humanizada e próxima de quem se cuida, seja no âmbito individual ou coletivo.

\section{ABSTRACT \\ Thematic sensorial station: a pedagogical resource for training the dentist in the production of healthcare}

The thematic sensorial station is a pedagogical resource that uses photographic images and/or objects in a given classroom space ("station"). Thus, students can feel objects using their five senses to bring them to reflections. This resource was proposed in the training of dental surgeons, to sensitize the participants in the production of health care, especially in the professional conduct to be taken in different contexts. This article intends to present the results of the application of the thematic sensorial station as pedagogical practice in the training of the dental surgeon, based on the experience developed in the area of public health, in the dentistry course.
It is an experience report and has a descriptive and reflective approach. The application of this pedagogical resource focused on the five senses is innovative in the teaching-learning process and also favors the awareness of professional practice to be felt and developed in a humanized way, individually or collectively.

Descriptors: Concept Formation. Health Education. Dentistry. Education, Dental.

\section{REFERÊNCIAS}

1. Bedrikow R, Campos GWS. História da Clínica e Atenção Básica: o desafio da ampliação. 2.ed. São Paulo: Hucitec, 2015.

2. Guyton AC, Hall JE. Tratado de Fisiologia Médica. 11.ed. Rio de Janeiro: Elsevier, 2006.

3. Brasil. Ministério da Saúde. SecretariaExecutiva. Núcleo Técnico da Política Nacional de Humanização. HumanizaSUS: Política Nacional de Humanização: a humanização como eixo norteador das práticas de atenção e gestão em todas as instâncias do SUS / Ministério da Saúde, Secretaria Executiva, Núcleo Técnico da Política Nacional de Humanização. Brasília: Ministério da Saúde, 2004.

4. Moreira MA, Caballero MC, Rodríguez ML (Orgs.) (1997). Actas del Encuentro Internacional sobre el Aprendizaje Significativo. Burgos, España. pp. 19-44. [Acesso em: 10 ago. 2017]. Disponível em: http://www.if.ufrgs.br/ moreira/apsigsubpor t.pdf.

5. Minayo MCS. O desafio do conhecimento: pesquisa qualitativa em saúde. 10ed. São Paulo: Hucitec; 2007.

6. Brasil. Ministério da Educação. Resolução CNE/CES 3, de 19 de fevereiro de 2002. Institui as Diretrizes Curriculares Nacionais do Curso de Graduação em Odontologia. Brasília, 2002.

7. Buss PM, Pellegrini Filho A. A saúde e seus 
determinantes sociais, Physis. 2007 17(1) :77-93.

8. Brasil. Ministério da Saúde. Secretaria de Atenção à Saúde. Política Nacional de Humanização da Atenção e Gestão do SUS. Clínica ampliada e compartilhada / Ministério da Saúde, Secretaria de Atenção à Saúde, Política Nacional de Humanização da Atenção e Gestão do SUS. - Brasília: Ministério da Saúde, 2009.

9. Oliveira GN. O projeto terapêutico singular. In: Campos GWS, Guerrero AVP (Orgs.). Manual de práticas de atenção básica: saúde ampliada e compartilhada. 3ed. São Paulo: Hucitec, 2023. p.283-297.

10. Pimenta SG, Anastasiou, LGC. Docência no ensino superior. São Paulo: Cortez, 2002.

11. Bedrikow R. A Clínica e as Políticas Públicas de Saúde para a Atenção Básica no Brasil. 2013. 199f. Tese (Doutorado em Ciências Médicas) - Faculdade de Ciências Médicas, Universidade Estadual de Campinas, Campinas, São Paulo.

12. Mendes EV. A evolução histórica da prática médica: suas implicações no ensino, na pesquisa e na tecnologia médicas. Belo Horizonte: PUC-MC/FINEP, 1984.
13. Fonsêca GS, Junqueira SR, Botazzo C, Carvalho YM, Araujo ME. A clínica do corpo sem boca. Saúde Soc. 2016; 25(4):1039-49.

14. Fonsêca GS, Junqueira SR, Araújo MC, Botazzo C. Modelo lógico-ideal para o estágio curricular supervisionado: a educação pelo trabalho na formação Odontológica. Rev ABENO. 2015;15(2):2-11.

15. Brasil. Ministério da Saúde. Gabinete do Ministro. Portaria $\mathrm{n}^{\mathrm{o}} 2.488$, de 21 de outubro de 2011. Aprova a Política Nacional de Atenção Básica, estabelecendo a revisão de diretrizes e normas para a organização da Atenção Básica, para a Estratégia Saúde da Família - ESF e o Programa de Agentes Comunitários de Saúde - PACS. Diário Oficial da República Federativa do Brasil, Brasília, DF, 24 out. 2011.

Correspondência para:

Lila Louise Moreira Martins Franco e-mail: lila80louise@yahoo.com.br Av. Perimetral Leste, 284 - Residencial San Marco Rua 1, Casa 7, Setor Anápolis City 75094-510 - Anápolis, GO 